\title{
Assessing the Quality of Various Preparations of Calendula officinalis using High Performance Thin Layer Chromatography
}

Snezana Agatonovic-Kustrin ${ }^{1 *}$, Anindita Chakrabarti ${ }^{1}$, David W Morton ${ }^{1}$ and Pauzi A Yusof ${ }^{2}$

${ }^{1}$ School of Pharmacy and Applied Science, La Trobe Institute of Molecular Sciences, La Trobe University, Edwards Rd, Bendigo, 3550, Australia

${ }^{2}$ Physiology Department, Medical School, Universiti Teknologi Mara, Selangor, Malaysia

\begin{abstract}
The primary goal of this study was to develop a simple and reliable High-Performance-Thin-Layer Chromatography method to quantitate active ingredients in commercial topical formulations containing Calendula officinalis extract and to investigate the affect of different extraction solvents on the overall quality of the formulation.

The developed method was validated for linearity, precision, accuracy, limit of detection, and limit of quantification. It was found that commercially available formulations containing extracts of Calendula officinalis have significant variations in both composition and amounts of active pharmaceutical ingredients, due to different extraction procedures employed and the standardization requirements
\end{abstract} for extracts used in formulation.

Keywords: Marigold; Calendula officinalis; High performance thin layer chromatography; Chlorogenic acid

\section{Introduction}

Calendula officinalis of the family Asteraceae, native to Eastern Europe and the Mediterranean, has long been used in both traditional and clinical medicine in wound healing and to help relieve skin inflammations and irritations [1-4]. It is commonly known as marigold, gold bloom and holligold. The anti-inflammatory and anti-oedematous properties of Calendula officinalis have been linked to the pentacyclic mono-, di- and trihydroxy triterpenoid fatty acid esters, especially the faradiol esters, faradiol 3-O-laurate, faradiol 3-O-palmitate and faradiol 3-O-myristate (Figure 1) [5-10]. The unesterified faradiol produced by hydrolysis, has been found to have the same effect as an equimolar dose of indomethacin which is a Non-Steroidal Anti-Inflammatory Drug (NSAID) [11]. However, the claimed benefits of these herbal formulations cannot be guaranteed in commercially available preparations unless standardised methods of regulation and testing are introduced. Thus, it has been suggested that the concentrations of the triterpenoid fatty acid esters in Calendula officinalis formulations may be an effective method to assess and monitor the quality of products on the market [9].

Since the dried ray and disk florets of the Calendula officinalis

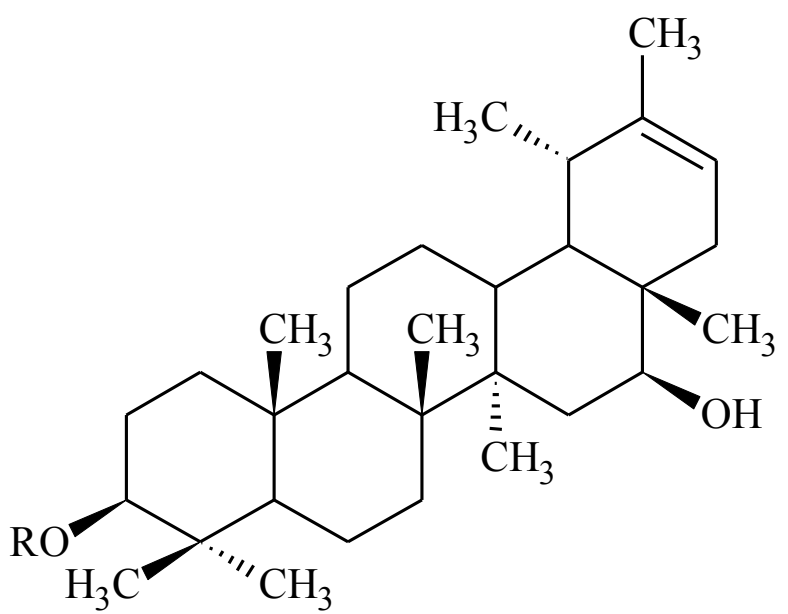

Figure 1: Structure of faradiol 3-O- monoesters; $\mathrm{R}=$ laurate, palmitate or myristate. flower contain the greatest quantities of the faradiol esters [6], European Pharmacopoeia recommends the use of the ligulate ray florets in the production of herbal medicinal products $[6,12]$. Also, growing and harvesting conditions can affect the chemical composition of Calendula officinalis. For example in a study conducted in Brazil [13] the total yield of essential oils obtained from Brazilian flowers was significantly lower than that obtained from another study conducted in France [14]. This was attributed to the difficulties of acclimatization of the plant from the lower temperatures in native areas of France when compared to the higher temperatures in Brazil.

The main aim of this study was to separate and compare different lipophilic extracts from Calendula officinalis flowers using chlorogenic acid as a phytochemical marker. It has been reported that the lipophilic ethyl acetate soluble fraction of the methanol extract of Calendula officinalis flowers exhibits the most potent inhibition $(84 \% \mathrm{w} / \mathrm{v})$ of induced inflammation when compared with indomethacin as a reference drug. Alternatively, an aqueous-ethanol extract showed only $20 \% \mathrm{w} / \mathrm{v}$ inhibition of inflammation [8]. However, a number of different extraction methods of Calendula officinalis, such as alcoholic and freeze-dried extractions, are used in the manufacture of Calendula officinalis formulations. Faradiol esters $[9,10,15]$, the active ingredients, are more soluble in less polar solvents so the method of extraction employed may influence the overall anti-inflammatory activity of Calendula officinalis in commercially available products. Another aim of this study was to quantitatively analyze active ingredients in commercially available topical creams and ointments, and to determine how different extraction methods of Calendula officinalis flowers affect the overall quality of the product.

Several analytical techniques have been established for the identification and quantification of natural products in herbal

*Corresponding author: Snezana Agatonovic-Kustrin, School of Pharmacy and Applied Science, La Trobe Institute of Molecular Sciences, La Trobe University, Edwards Rd, Bendigo, 3550, Australia, Tel: +613-544-473-60; E-mail: s.kustrin@latrobe.edu.au

Received November 17, 2013; Accepted December 16, 2013; Published December 23, 2013

Citation: Agatonovic-Kustrin S, Chakrabarti A, Morton DW, Yusof PA (2013) Assessing the Quality of Various Preparations of Calendula officinalis using High Performance Thin Layer Chromatography. Mod Chem appl 1: 115 doi:10.4172/2329-6798.1000115

Copyright: (C) 2013 Agatonovic-Kustrin S, et al. This is an open-access article distributed under the terms of the Creative Commons Attribution License, which permits unrestricted use, distribution, and reproduction in any medium, provided the original author and source are credited. 
preparations. However, some of these procedures (e.g. high performance liquid chromatography) are time-consuming, have high operational costs, and also require high technical skills together with sophisticated equipment. Quantitative Thin Layer Chromatography (TLC) has been used widely for analysis of herbal medicinal extracts due to its simplicity of operation, speed, versatility and reproducibility, and relatively low cost, as a number of samples can be analyzed simultaneously on a single plate using only a small amount of solvent as the mobile phase [16-20] (Figure 1).

\section{Experimental}

\section{Materials}

The standardized Calendula officinalis $\mathrm{CO}_{2}$ extract was obtained from The Herbarie (Batch: 0809, The Herbarie at Stoney Hill Farm, Inc, Prosperity, NC, USA) which contains $6.0-7.0 \%$ faradiol esters, $0.25 \%$ carotenoids and $0.27 \%$ essential oils in fractionated coconut oil. Four different topical formulations, two creams ( $\mathrm{C} 1$ and $\mathrm{C} 2)$ and two ointments (O1 and $\mathrm{O} 2)$ were obtained from manufacturers in Australia and Italy. The samples included the following manufacturers claims; Calendula officinalis cream C1 containing Marigold flowers freezedried extract $1 \%$ (standardized to $1.2 \%$ total flavonoids expressed as hyperoside) (Italy), Calendula officinalis cream C2 containing $10 \mathrm{~mL}$ in $100 \mathrm{~g}$ of Calendula officinalis extract (1:5) in aqueous cream (Australia), Homeopathic Calendula officinalis 10\% Ointment O1 (Italy) and Calendula officinalis ointment $\mathrm{O} 2$ containing Calendula officinalis extract equivalent to $71 \mathrm{mg}$ dry flower per $1 \mathrm{~g}$ (Australia). Solvents used in the HPTLC mobile phase were ethyl acetate, anhydrous $99.8 \%$ (Sigma Aldrich, Germany), n-hexane 95.0\% (BDH, England), and/ or glacial acetic acid 99.8\% (Sigma Aldrich, Germany). Extraction solvents used were dichloromethane 99.5\% (Chem-supply, Australia) or ethanol 95.0\% (Sigma Aldrich, Germany). Chlorogenic acid or 5-caffeoylquinic acid, minimum 95\% (Sigma Aldrich, Germany), was used as an external standard.

\section{Methods}

Standard calibration line: A Calendula standard solution was

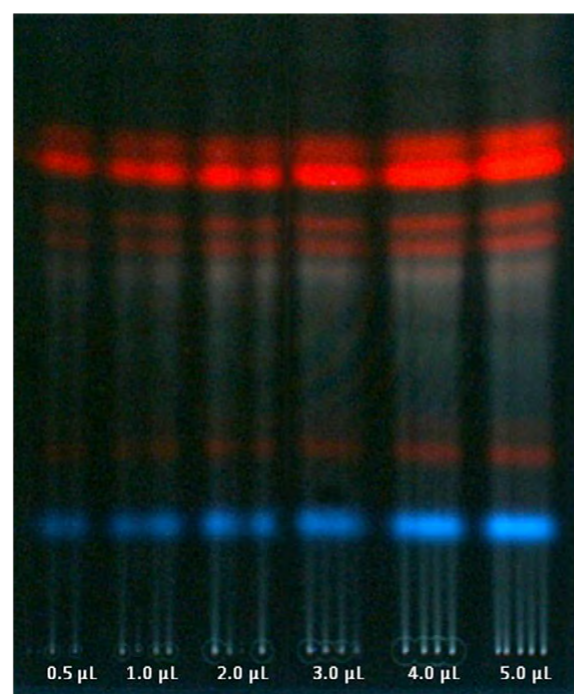

Chlorogenic acid

Figure 2: HPTLC chromatogram of standardized Calendula officinalis $\mathrm{CO}_{2}$ extract in dichloromethane solvent. Mobile phase; n-hexane: ethyl acetate: acetic acid in a ratio of $20: 10: 1(\mathrm{v} / \mathrm{v} / \mathrm{v})$. Spotted from left to right with $0.5 \mu \mathrm{L}, 1$ $\mu \mathrm{L}, 2 \mu \mathrm{L}, 3 \mu \mathrm{L}, 4 \mu \mathrm{L}$, and $5 \mu \mathrm{L}$ of solution. prepared by transferring $5.00 \mathrm{~mL}$ of standardized Calendula officinalis $\mathrm{CO}_{2}$ extract of the flower to a $50.0 \mathrm{~mL}$ volumetric flask and making it up to volume with dichloromethane. This solution was spotted onto a HPTLC plate in increasing volumes from $0.50-5.0 \mu \mathrm{L}$ (Figure 2). The plate was developed in a mobile phase of $n$-hexane: ethyl acetate: acetic acid in a ratio of 20:10:1 (v/v/v). A chlorogenic acid standard curve was prepared by spotting $1.0-10.0 \mu \mathrm{L}$ of a $1.0 \mathrm{mg} / \mathrm{mL}$ chlorogenic acid in ethanol. The plate was developed in a mobile phase of $n$-hexane: ethyl acetate: acetic acid in a ratio of 20:10:1 (v/v/v).

Extraction protocols: Samples of organic dried Calendula officinalis flowers were obtained from an Australian source (Batch: OCOFOO3EH, All Rare Herbs, Queensland). These flower samples were manually separated to obtain yellow petal (ray floret), green stem (disc floret) and whole flower samples. Ground flower samples $(1 \mathrm{~g})$ were extracted either using dichloromethane or ethanol and then filtered using $7.0 \mathrm{~cm}$ round filter paper (Whatman, England) and made up to $50 \mathrm{~mL}$ in volumetric flasks. Solvent extraction involved heating at approximately $60^{\circ} \mathrm{C}$ while stirring and then leaving the sample for 24 hours. Freeze dried samples were also prepared using dried flowers that were placed in a freeze drier for 48 hours and then extracted in a similar method using either dichloromethane or ethanol. The extracts stored at $4^{\circ} \mathrm{C}$ were very stable, having the same qualitative and quantitative composition after 1 month of storage. This is to be expected as flavonoids are substances which generally have a high chemical stability [21].

Alcoholic or dichloromethane extracts from creams and ointments were prepared by mixing $2 \mathrm{~g}$ of the formulation in either $15 \mathrm{~mL}$ of ethanol or dichloromethane and heating it at $60^{\circ} \mathrm{C}$, stirring until dissolved. The solution was then filtered using $7.0 \mathrm{~cm}$ round filter paper (No. 1, Whatman, England) into a $25 \mathrm{~mL}$ volumetric flask and made up to volume. $10 \mu \mathrm{L}$ of each extract was directly applied onto HPTLC plates in triplicate and the chromatograms developed and analyzed.

Quantitative HPTLC analysis: Samples were directly applied onto HPTLC Silica gel 60 F254 plates (Merck, Switzerland) $(10 \times 10$ $\mathrm{cm}$ ) using a Nanomat 4 applicator (Serial: 1611, Camag, Muttenz, Switzerland) or using a $10 \mu \mathrm{L}$ guided plunger syringe (Serial: 10R-GP, SGE, Australia). The distance between the sample bands was set at 10 $\mathrm{mm}$; the distance from the lower plate edge was $8 \mathrm{~mm}$, with 8 bands spotted per plate. Since faradiol esters are not commercially available, a quantitative comparison was carried out according to the external standard method. Chlorogenic acid was used as a reference standard to compare the phytochemical composition in the extracts of flowers and extracts from the commercial formulations.

Plates were developed using saturated vertical twin trough developing chambers $(10 \times 10 \mathrm{~cm}, 10 \times 20 \mathrm{~cm})$ and also using a horizontal $(10 \times 10 \mathrm{~cm})$ developing chamber (Camag, Muttenz, Switzerland) with n-hexane:ethyl acetate:acetic acid $(20: 10: 1, \mathrm{v} / \mathrm{v} / \mathrm{v})$ as the mobile phase. The solvent front was allowed to develop until it had travelled a distance of $80 \mathrm{~mm}$ which took approximately 25 minutes. After drying the plates with a stream of cold air for 1 minute, the spots were examined using a TLC-Visualiser (Camag, Muttenz, Switzerland) under transmitted white light at wavelengths of UV $254 \mathrm{~nm}$ and UV $366 \mathrm{~nm}$. Images from developed HPTLC plates were digitally captured using a highresolution 12 bit CCD. Fixed capture parameters (focal length, focus, and aperture) ensured high reproducibility of images from plate to plate [22]. The Just TLC (Sweday,, Sweden) analysis program was used to quantify and compare the area of each spot from the captured chromatogram images. 


\section{Results and Discussion}

\section{Analytical characteristics of the HPTLC Method}

The experimental purpose of this work was to develop a simple and reliable HPTLC procedure for the quantification of active constituents in lipid extracts of Calendula officinalis. The first step in chromatographic method development was to select an appropriate mobile phase so that $\mathrm{Rf}$ values for the components are between 0.3-0.5. Initial trials with a number of different mobile phases were guided by previous work $[5,6,11,23]$, which included varying ratios of n-hexane, ethanol, ethyl acetate, dichloromethane and acetonitrile. Good separation was previously achieved using a solvent mix of $n$-hexane: ethyl acetate in a ratio of $8: 2(\mathrm{v} / \mathrm{v})[6]$. However, the bands tended to merge into each other. Several mobile phases with small amounts of acid modifier to improve separation were investigated. An increase in acidity of the mobile phase by the addition of acetic acid improved the overall separation of compounds. The optimal mobile phase to separate the compounds in Calendula officinalis was found to be n-hexane: ethyl acetate: acetic acid in a ratio of 20:10:1 (v/v/v) (Figure 2).

Using the optimal mobile phase mixture, qualitative TLC analysis of the extracts generally revealed seven bands upon development, with the light blue fluorescent zone at an $\mathrm{R}_{\mathrm{f}}=0.30$, corresponding to chlorogenic acid. Note: the chlorogenic acid band is the lowest visible band in Figure 2. Captured color images were visually evaluated and Just TLC software was then used to calculate the area (in pixels) of the bands. The concentration of chlorogenic acid in each extract was determined using a standard curve prepared with chlorogenic acid and was expressed as the weight of chlorogenic acid in $100 \mathrm{~mL}$. It was found that $100 \mathrm{~mL}$ of the standardized Calendula officinalis $\mathrm{CO}_{2}$ extract contains $16.750 \mathrm{~g}$ of chlorogenic acid or $16.75 \%(\mathrm{w} / \mathrm{v})$.

\section{Evaluation of the extraction procedures}

Ethanoland dichloromethane were used to extract activecomponents from standard $\mathrm{CO}_{2}$ extracts of Calendula officinalis in order to determine if there is a difference in the amount of active ingredients present in a formulation as a result of the type of solvent used for the extraction. The results of TLC analyses show that dichloromethane extracts dissolved a greater amount of active ingredients from the raw sample than ethanol extracts, as evident in larger band area of chlorogenic acid (2717 pixels with dichloromethane compared to 1827 pixels with ethanol used as extraction solvent). Dichloromethane extracts contained a greater amount and variety of chemical compounds as identifiable, intensely colored bands on the HPTLC plates, in comparison to ethanol extracts. This is supported by previous work that suggests that the active antiinflammatory faradiol esters in Calendula officinalis are more soluble in less polar organic solvents such as dichloromethane [7]. Extractions using individual parts of fresh flowers (i.e. yellow petals and green stems) of C. officinalis were performed in order to determine if there are significant differences in the chemical composition of these parts. After extraction (dichloromethane and ethanol), extracts were investigated by HPTLC. Compounds with higher $\operatorname{Rf}(\geq 0.6)$ were present in higher amounts in the extracts obtained from the yellow petals, while green stem extracts contained higher amounts of chlorogenic acid $\left(\mathrm{R}_{\mathrm{f}}=0.30\right)$.

The influence of freeze-drying on sample preparation was analyzed by comparing freeze-dried to non-freeze-dried samples. The nonfreeze-dried samples contained an identifiable band for chlorogenic acid, which was absent from the freeze-dried samples. The samples that had not been freeze-dried also displayed bands of greater intensity. This indicates that extraction using dichloromethane and ethanol solvents may be more effective using dry flowers that have not been freeze-dried.

\section{Method validation}

The method was validated by testing results for linearity, accuracy, precision, reproducibility, ruggedness and specificity [24,25]. The linearity of the method was established by calculating the areas of the bands for chlorogenic acid from plates spotted with varying concentrations of standardized Calendula officinalis $\mathrm{CO}_{2}$ extract. Two bands on the plate, with $\mathrm{Rf}$ values of 0.3 (chlorogenic acid) and 0.7 respectively were selected. The calibration curves were constructed by plotting spot area against applied concentration. The linearity of the calibration curves and the adherence of the method to Beer's law are validated by the high value of the correlation coefficient and the value of intercept on ordinate which is close to zero. The calibration lines demonstrated a linearity (coefficient of correlation) of $0.991 \quad\left(R_{\mathrm{f}}=0.30\right)$ and $0.962\left(\mathrm{R}_{\mathrm{f}}=0.7\right)$, respectively, in the investigated volume range 0.05 $0.5 \mu \mathrm{L}$ of standardized extract.

The area of the bands versus applied amount of standardized extract were plotted to obtain the calibration graph. Both bands obeyed the Beer's law within the investigated concentration range. Rather than to test the significance of the intercept of the line, we wanted to investigate if the equations provide an adequate fit to the experimental data. In order to test the overall fit of the linear regression model and the significance of the regression parameters, analysis of variance (ANOVA) was performed. ANOVA analysis was used to test how variations in the response (concentration of dichloromethane standard sample applied to the plates) affect the variation in responses (band area). High correlation coefficients indicate the good fit of the model to a data. However, they are not the best measure of the effectiveness of the model. Thus, we have tested the effectiveness of the areas of the bands in explaining the model and fitting to the concentration by the Fisher variance ratio (F). The F-test is the ratio of two scaled sums of squares reflecting different sources of variability, so that the calculated $\mathrm{F}$ value should be smaller than the critical value, if the hypothesis that the model has no predictive capability is true (null hypothesis). The null hypothesis is rejected if the $\mathrm{F}$ ratio is large. The values of $\mathrm{F}$ for calibration obtained using band 1 and 2 were 221.63 and 49.18, respectively. These $\mathrm{F}$ values were significantly greater than the critical tabular value at a given level of confidence (Fcrit=7.71) indicating that there is not a significant amount of variation in the measured areas that is not explained by the model. Thus, there is not a significant lack of fit between the model and the data.

Band 1 corresponding to chlorogenic acid was selected in order to validate the method in accordance with International Conference on Harmonization (ICH) [26,27] guidelines for method validation. The Limit of Detection (LOD) and Limit of Quantification (LOQ) were calculated according to ICH guidelines [27]. The average LOD, the lowest concentration (amount) of analyte in a sample that can be detected but not necessarily quantified, was $0.02156 \mu \mathrm{L}$ of the standard solution which corresponds to $2.15 \mathrm{~nL}$ of the standardized extract. The LOD is frequently confused with the sensitivity of the method. The sensitivity of an analytical method is the capability of the method to discriminate small differences in the concentration of the test analyte. In practical terms, sensitivity is the slope of the calibration curve that is obtained by plotting the response against the analyte concentration. The LOQ or the minimum concentration that produces quantitative response with acceptable precision was $6.533 \mathrm{~nL}$ of the standardized extract.

The International Conference on Harmonization (ICH) guideline for method precision [27] requires precision from at least 9 replications covering the complete investigated concentration range. In this study, 
Citation: Agatonovic-Kustrin S, Chakrabarti A, Morton DW, Yusof PA (2013) Assessing the Quality of Various Preparations of Calendula officinalis using High Performance Thin Layer Chromatography. Mod Chem appl 1: 115. doi:10.4172/2329-6798.1000115

Page 4 of 5

\begin{tabular}{|c|c|c|c|c|c|c|c|}
\hline Volume ( $\mu \mathrm{L})$ & Sample 1 (Pixels) & Sample 2 (Pixels) & Sample 3 (Pixels) & $S^{a}$ & LOD $^{b}$ & $\operatorname{LOQ}^{c}$ & $\operatorname{RSD}(\%)^{\mathrm{d}}$ \\
\hline 1 & 251 & 243 & 251 & 4.62 & 0.032 & 0.098 & 1.86 \\
\hline 2 & 375 & 371 & 375 & 2.31 & 0.016 & 0.049 & 0.62 \\
\hline \multirow[t]{2}{*}{3} & 523 & 523 & 527 & 2.31 & 0.016 & 0.049 & 0.44 \\
\hline & & & Average & 3.08 & 0.022 & 0.065 & 0.97 \\
\hline
\end{tabular}

aStandard deviation

bLimit of detection

cLimit of quantification

dRelative standard deviation (\%).

Table 1: Method validation for the determination of chlorogenic acid concentration from plates spotted with varying volumes of standardized Calendula officinalis $\mathrm{CO}_{2}$ extract solution $\left(\mathrm{CH}_{2} \mathrm{Cl}_{2}\right.$ solvent).

\begin{tabular}{|c|c|c|c|}
\hline $\begin{array}{c}\text { Cream/ointment } \\
\text { extract }\end{array}$ & $\begin{array}{c}\text { Extraction } \\
\text { solvent }\end{array}$ & $\begin{array}{c}\text { Overall pixel count for the bands observed on the } \\
\text { HPTLC plate }\end{array}$ & Amount of chlorogenic acid (mg/100g) \\
\hline $\mathrm{C} 1 \mathrm{~d}$ & $\mathrm{CH}_{2} \mathrm{Cl}_{2}{ }^{*}$ & 1991 \\
\hline $\mathrm{C} 1 \mathrm{e}$ & ethanol & 1695 \\
\hline $\mathrm{C} 2 \mathrm{~d}$ & $\mathrm{CH}_{2} \mathrm{Cl}_{2}$ & 1455 \\
\hline $\mathrm{C} 2 \mathrm{e}$ & ethanol & 1129 \\
\hline $\mathrm{O} 1 \mathrm{~d}$ & $\mathrm{CH}_{2} \mathrm{Cl}_{2}$ & 500 \\
\hline O1e & ethanol & 485 \\
\hline
\end{tabular}

${ }^{*} \mathrm{CH}_{2} \mathrm{Cl}_{2}=$ dichloromethane

Table 2: Overall pixel count $(n=3)$ for bands observed for each cream extract on the HPTLC plate.

the results were obtained at 3 different concentrations with 3 replicates at each concentration (Table 1). Instrumental precision was checked by replicate scanning of the same bands of a selected concentration of Calendula officinalis standardized extract and expressed as percentage Relative Standard Deviation (RSD, \%) of areas; the average RSD ( $\mathrm{n}=9$ ) was $0.97 \%$. The variability of the method was studied by analyzing selected diluted extracts on the same day (intraday precision), and on different days after an interval of three days (interday precision); results were then again expressed as RSD (\%). The intraday precision was found to be $0.65 \%$ and the interday precision was found to be $1.69 \%$, highlighting the unstable nature of the Calendula officinalis samples. This variability was reduced by spotting samples on the day of preparation and storing the images of HPTLC plates digitally (Table 1).

\section{Analysis of topical formulations}

The proposed method was successfully applied to 4 topical formulations, two creams ( $\mathrm{C} 1$ and $\mathrm{C} 2)$ and two ointments (O1 and $\mathrm{O} 2$ ). A number of the components in each extract were separated using HPTLC and the concentration of chlorogenic acid (mg in $100 \mathrm{~g}$ cream/ ointment) determined. As indicated in Table 2, sample extracts from $\mathrm{C} 1$ (Italian cream) obtained with dichloromethane (C1d) and with ethanol (C1e) have significantly higher concentrations of chlorogenic acid compared to sample extracts $\mathrm{C} 2 \mathrm{~d}$ and $\mathrm{C} 2 \mathrm{e}$ (Australian creams). The data in Table 2 also indicates that ethanol was less effective compared to dichloromethane in extracting chlorogenic acid from the cream and ointment samples. For the ointments, chlorogenic acid was only quantifiable in the homeopathic Italian ointment extracts (O1d and O1e) in contrast to the Australian ointment extracts where identifiable spots for chlorogenic acid were not visible. Note that the Italian ointment extracts contained much lower concentrations of chlorogenic acid (around 6 times less) compared to the creams investigated (Table 2).

In general, the results of the HPTLC analyses, indicates that the Italian cream has a greater number of high intensity identifiable bands when compared to the Australian cream regardless of the extraction solvent used.

\section{Conclusion}

This study has demonstrated the need for standardized testing and regulation of herbal products available to consumers. The commercially available formulations of Calendula officinalis have been shown to significantly differ in composition. This work demonstrates that the variations between extraction methods and pharmaceutical dosage forms have considerable impact on the concentration of active ingredients in that product. The literature to support the efficacy of Calendula officinalis as an anti-inflammatory cream is strongly supported by evidence [9]; however, the benefits of these available products cannot be guaranteed if appropriate quality control measures and standards are not implemented. Scope for future study includes the development of methods to purify and obtain samples of faradiol esters present in Calendula officinalis in order to quantify the amounts of these esters present in Calendula officinalis cream and ointment formulations. This study has developed a simple and reliable method for the HPTLC separation of compounds in Calendula officinalis formulations. The method is both rapid and sensitive which makes it ideal for routine analysis of formulations containing Calendula officinalis extracts.

\section{References}

1. Basch E, Bent S, Foppa I, Haskmi S, Kroll D, et al. (2006) Marigold (Calendula officinalis L.): an evidence-based systematic review by the Natural Standard Research Collaboration. J Herb Pharmacother 6: 135-159.

2. Muley BP, Khadabadi SS, Banarase NB (2009) Phytochemical Constituents and Pharmacological Activities of Calendula officinalis Linn (Asteraceae): A Review. Trop J Pharm Res 8: 455-465.

3. Fuchs SM, Schliemann-Willers S, Fischer TW, Elsner P (2005) Protective effects of different marigold (Calendula officinalis L.) and rosemary cream preparations against sodium-lauryl-sulfate-induced irritant contact dermatitis. Skin Pharmacol Physiol 18: 195-200.

4. Fronza M, Heinzmann B, Hamburger M, Laufer S, Merfort I (2009) Determination of the wound healing effect of Calendula extracts using the scratch assay with 3 T3 fibroblasts. J Ethnopharmacol 126: 463-467.

5. Hamburger M, Adler S, Baumann D, Förg A, Weinreich B (2003) Preparative purification of the major anti-inflammatory triterpenoid esters from Marigold (Calendula officinalis). Fitoterapia 74: 328-338.

6. Zitterl-Eglseer K, Reznicek G, Jurenitsch J, Novak J, Zitterl W, et al. (2001) Morphogenetic variability of faradiol monoesters in marigold Calendula officinalis L. Phytochem Anal 12: 199-201.

7. Baumann D, Adler S, Griiner S, Otto F, Weinreich B, et al. (2004) Supercritical carbon dioxide extraction of marigold at high pressures: comparison of analytical and pilot-scale extraction. Phytochem Anal 15: 226-230. 
Citation: Agatonovic-Kustrin S, Chakrabarti A, Morton DW, Yusof PA (2013) Assessing the Quality of Various Preparations of Calendula officinalis using High Performance Thin Layer Chromatography. Mod Chem appl 1: 115. doi:10.4172/2329-6798.1000115

8. Ukiya M, Akihisa T, Yasukawa K, Tokuda H, Suzuki T, et al. (2006) Antiinflammatory, anti-tumor-promoting, and cytotoxic activities of constituents of marigold (Calendula officinalis) flowers. J Nat Prod 69: 1692-1696.

9. Della Loggia R, Tubaro A, Sosa S, Becker H, Saar S, et al. (1994) The role of triterpenoids in the topical anti-inflammatory activity of Calendula officinalis flowers. Planta Med 60: 516-520.

10. Neukirch H, D’Ambrosio M, Sosa S, Altinier G, Della Loggia R, et al. (2005) Improved anti-inflammatory activity of three new terpenoids derived, by systematic chemical modifications, from the abundant triterpenes of the flowery plant Calendula officinalis. Chem Biodivers 2: 657-671.

11. Zitterl-Eglseer K, Sosa S, Jurenitsch J, Schubert-Zsilavecz M, Della Loggia $R$, et al. (1997) Anti-oedematous activities of the main triterpendiol esters of marigold (Calendula officinalis L.). J Ethnopharmacol 57: 139-144.

12. (2007) European Pharmacopoeia, sixth edition, Directorate for the Quality of Medicines \& HealthCare of the Council of Europe (EDQM), Strasbourg.

13. Gazim ZC, Rezende CM, Fraga SR, Filho BPD, Nakamura CV, et al. (2008) Analysis of the essential oils from Calendula officinalis growing in Brazil using three different extraction procedures. Rev Bras Cienc Farm 44: 391-395.

14. Chalchat JC, Garry RPH, Michet A (1991) Chemical composition of essentia oil of Calendula officinalis L. (pot marigold). Flavour and Fragrance Journal 6 : 189-192.

15. Loggia RD, Becker $H$, Issac O, Tubaro A (1990) Topical anti-inflammatory activity of Calendula officinalis extracts. Planta Med 56: 658-659.

16. Kivçak B, Akay S (2005) Quantitative determination of alpha-tocopherol in Pistacia lentiscus, Pistacia lentiscus var. chia, and Pistacia terebinthus by TLCdensitometry and colorimetry. Fitoterapia 76: 62-66.

17. Kivçak B, Mert T (2001) Quantitative determination of alpha-tocopherol in Arbutus unedo by TLC-densitometry and colorimetry. Fitoterapia 72: 656-661.
8. Apers S, Naessens T, Pieters L, Vlietinck A (2005) Densitometric thin-layer chromatographic determination of aescin in a herbal medicinal product containing Aesculus and Vitis dry extracts. J Chromatogr A 1112: 165-170.

19. Gunther M, Schmidt PC (2005) Comparison between HPLC and HPTLCdensitometry for the determination of harpagoside from Harpagophytum procumbens $\mathrm{CO}(2)$-extracts. J Pharm Biomed Anal 37: 817-821.

20. Fang C, Wan X, Jiang C, Cao H (2005) Comparison of HPTLC and HPLC for determination of isoflavonoids in several kudzu samples. JPC - Journal of Planar Chromatography - Modern TLC 18: 73-77.

21. Crawford DJ, Giannasi DE (1982) Plant chemosystematics. Bioscience 32: 114

22. (2010) CAMAG Laboratory, Parameters of Planar Chromatography.

23. Cetkovic GS, Djilas SM, Canadanovic-Brunet JM, Tumbas VT (2003) Thinlayer chromatography analysis and scavenging activity of marigold (Calendula officinalis L.) extracts. APTEFF 34: 93-102.

24. Reich E, Schibli A, DeBatt A (2008) Validation of high-performance thinlayer chromatographic methods for the identification of botanicals in a cGMP environment. J AOAC Int 91: 13-20.

25. Kumar V, Mukherjee K, Kumar S, Mal M, Mukherjee PK (2008) Validation of HPTLC method for the analysis of taraxerol in Clitoria ternatea. Phytochem Anal 19: 244-250.

26. Ferenczi-Fodor K, Végh Z, Nagy-Turák A, Renger B, Zeller M (2001) Validation and quality assurance of planar chromatographic procedures in pharmaceutical analysis. J AOAC Int 84: 1265-1276.

27. Green JM (1996) A practical guide to analytical method validation, Internationa Conference on Harmonization (ICH) of Technical Requirements for the Registration of Pharmaceuticals for Human Use. Anal Chem, Geneva, pp. 305A-309A 